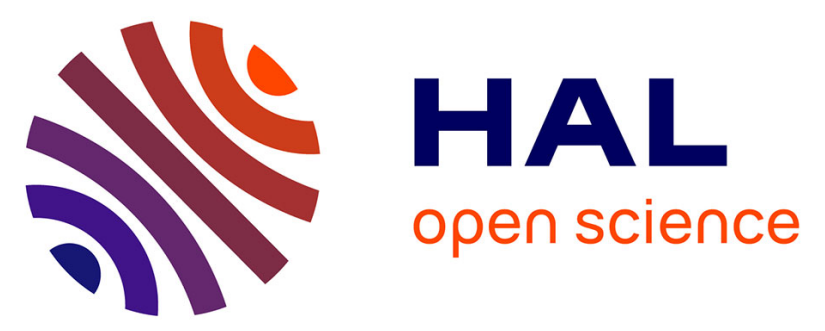

\title{
Recommendation of HPV vaccination to boys in Francean unhappy coïncidence with the WHO call to pause the implementation of this vaccination in boys
}

Fadia Dib, François Vie Le Sage, Robert Cohen, Odile Launay

\section{- To cite this version:}

Fadia Dib, François Vie Le Sage, Robert Cohen, Odile Launay. Recommendation of HPV vaccination to boys in Francean unhappy coïncidence with the WHO call to pause the implementation of this vaccination in boys. Vaccine, 2020, 38 (23), pp.3919-3921. 10.1016/j.vaccine.2020.04.017 . hal03126962

\section{HAL Id: hal-03126962 \\ https: / hal.sorbonne-universite.fr/hal-03126962}

Submitted on 1 Feb 2021

HAL is a multi-disciplinary open access archive for the deposit and dissemination of scientific research documents, whether they are published or not. The documents may come from teaching and research institutions in France or abroad, or from public or private research centers.
L'archive ouverte pluridisciplinaire HAL, est destinée au dépôt et à la diffusion de documents scientifiques de niveau recherche, publiés ou non, émanant des établissements d'enseignement et de recherche français ou étrangers, des laboratoires publics ou privés. 


\section{TITLE PAGE}

\section{Recommendation of HPV vaccination to boys in France - 3 an unhappy coïncidence with the WHO call to pause the 4 implementation of this vaccination in boys}

6 Fadia Dib1,2, François Vie le Sage3,4, Robert Cohen5,6, Odile Launay1,2,7

81 INSERM CIC 1417, F-CRIN, I REIVAC ; Assistance Publique- Hôpitaux de Paris, Hôpital

9 Cochin, Paris, France

102 INSERM, Sorbonne Université, Institut Pierre Louis d'Épidémiologie et de Santé Publique,

11 Paris, France

123 GPIP, Groupe de Pathologie Infectieuse Pédiatrique, Paris, France.

134 AFPA, Association Française de Pédiatrie Ambulatoire, Saint-Germain-en-Laye, France

145 Association Clinique et thérapeutique Infantile du Val de Marne, Saint-Maur des Fossés,

15 France.

16 Department of neonatology, CHI Creteil, Creteil, France.

177 Université de Paris, Faculté de médecine Paris Descartes; Paris, France

19 Corresponding author:

20 Pr. Odile Launay

21 CIC Cochin Pasteur (CIC 1417)

$22 \quad 27$ rue du Faubourg St Jacques

2375679 Paris cedex 14

24 e-mail: odile.launay@aphp.fr

25 Tel: +331466763 00; Fax: +33146676310

26 Short title: Extension of HPV vaccination to boys in France

27 Keywords: HPV vaccine, boys, recommendations, World Health Organization, vaccine

28 hesitancy, misinformation

29 Word count text=1465 words

30 References $=12$ 


\section{MANUSCRIPT}

33 While France was one of the first three countries in the world to introduce Human

34 Papillomavirus (HPV) vaccination for girls in 2006 (1), it has been lagging behind when it

35 comes to the introduction of HPV vaccine for boys from the general population. Indeed,

36 several countries have expanded HPV vaccination to boys (2). A number of arguments

37 could justify gender-neutral HPV vaccination, and in 2016, a push from patients'

38 associations in particular led to the French recommendation of HPV vaccination in men

39 who have sex with men, as they have an increased risk of exposure to and infection with 40 HPV.

42 On December 16 th 2019, the French National Authority for Health (HAS) finally issued a

43 recommendation for all boys aged 11 to 14 years to receive HPV vaccine, with possible

44 catch-up until the age of 19 years (3). It has been a long road to reach this milestone. A

45 citizen consultation on vaccination held in 2016 in France pushed among other things for

46 adoption of universal HPV vaccination of boys and girls. At the beginning of 2019, the

47 French Minister of Health declared that she was personally in favour of extending HPV

48 vaccination to boys and that she had referred the matter to the HAS the previous year. In

49 March 2019, a press release was put out by a collective of Academies, Colleges, Societies

50 and Medical Unions, leading medical personalities and patients' associations calling for

51 action to synergistically expand HPV vaccination to boys and strengthen cervical cancer

52 screening (4). In October 2019, the HAS issued a favourable opinion on the widespread

53 vaccination of boys and called for accompanying measures such as strengthening the 
54 recommendation of HPV vaccination by healthcare professionals and facilitating access to

55 HPV vaccination through full reimbursement by the national health insurance system. This

56 opinion was accompanied by an online public consultation of a draft recommendation for

57 the vaccination of boys at the ages mentioned above. Multiple considerations were taken

58 into account in the HAS recommendation, including the burden of HPV-related diseases in

59 men, the favourable opinion of the general practitioners who felt that vaccinating boys

60 would help increase the uptake of vaccination in girls -which remains low in France $23.7 \%$

61 for two-dose HPV vaccination among 16-year-olds, in 2018)- and ethical considerations

62 (according to the principle of equity in preventing diseases in both sexes). While this

63 recommendation represents a major step forward to promote gender-neutral HPV

64 vaccination in France, future challenges are foreseen. Now is the time to prepare to meet

65 these challenges, if the implementation of this recommendation is to be successful.

67 First, we need to be ready to correct misinformation (5) and strive to do this in a timely 68 manner. Anti-vaccination movements started even before the HAS recommendation was

69 issued. The benefit of vaccinating boys was put into question shortly (6) after the World

70 Health Organization (WHO) Strategic Advisory Group (SAGE) on immunization stated that

71 "All countries should temporarily pause implementation of boy, older age group (>15

72 years) and multi-age cohort (MAC) HPV vaccination strategies until vaccine supply allows

73 equitable access to HPV vaccine by all countries. This will significantly relieve supply

74 constraints in the short term and enable allocation of doses to high-burden countries that

75 are currently planning to introduce or sustain HPV vaccination" (7). The WHO call, which

76 was made on the grounds of equity and solidarity in the face of global HPV vaccine 
77 shortages, soon became an instrument to feed the anti-vax movement with claims that "If

78 this vaccination is really useful for boys, as some have repeatedly said, how can we explain

79 this WHO appeal which could appear to discriminate against boys?". This unfortunate use of

80 the WHO call must be addressed at the national and global levels and future

81 instrumentalization must be prevented. Equally disturbing are the claims stated in an

82 online petition that "We must protect our little girls but also soon our little boys from these

83 mass vaccination campaigns with Gardasil [...] If even the government closes its eyes and

84 blindly supports Gardasil, what can we do?". Historically, based on cost-effectiveness

85 considerations, selective vaccination programs for girls have first been implemented. This

86 selectivity possibly conveyed the message that HPV vaccine was not effective or

87 unimportant in boys. From an ethical point of view, it leaves us torn regarding the sex to 88 prioritize over the other.

90 Second, notwithstanding the reassuring safety data accumulated over the years and across

91 countries, safety issues of HPV vaccination have been raised repeatedly in France and other

92 parts of the world, fuelling anti-vax movements. People's concerns regarding HPV vaccine

93 safety issues must be heard and addressed. Confidence towards HPV vaccination must be

94 restored. After all, let us not forget that in France "one in three people disagree that

95 vaccines are safe" (8).

97 Third, we need to take into account the particular context of HPV vaccination of adolescent

98 girls in France. The reasons for the low uptake of HPV vaccine in French girls remain

99 unclear, are probably multifactorial and the subject of current research. However, vaccine 
100 hesitancy, which is recognized by the WHO as one of the 10 threats to global health (9), is

101 certainly one of the contributing factors. In France, growing vaccine hesitancy combined

102 with low uptake of certain vaccines have led the Ministry of Health to recommend extension

103 of mandatory vaccination for children as of January 1, 2018 from three to eleven

104 vaccinations (10). There is no apparent reason to expect that HPV vaccine hesitancy would

105 be limited to the case of girls. Lessons can be learned from the detailed examination of the

106 failed attempts to increase HPV vaccine uptake in girls in France. It is now widely

107 recognized that school-based vaccination programs have been successful in achieving high

108 HPV vaccine uptake (11) and should be (re)considered when expanding HPV vaccination to

109 boys. However, it appears a daunting task in France where a school-based vaccination

110 program against hepatitis B was discontinued as a result of the controversy over the alleged

111 causal link between hepatitis B vaccination and the development of multiple sclerosis, in

112 the 1990s (12). A lack of dedicated human resources within French school health services

113 may be an additional barrier for the successful deployment of a school-based HPV

114 vaccination program in France. Alternatively, in some countries such as Spain and Portugal,

115 high levels of HPV vaccination coverage are reached without school programs. Otherwise,

116 interventions on text messaging (reminder/recall) to parents have been tested and shown

117 promising results. Such an approach represents a scalable and sustainable strategy that

118 warrants wider consideration in France.

120 Finally, there needs to be a well-developed mass communication strategy in place to

121 support the introduction of HPV vaccine in boys. Such campaigns would represent a golden

122 opportunity to address low HPV vaccine uptake in girls, perhaps by repositioning it as an 
123 effective tool to prevent the infection by the most common sexually transmitted infection

124 which unfortunately can cause genital and extra-genital cancers in both sexes. Education

125 and communication campaigns should explain the sexual transmission nature of HPV and

126 promote the equal responsibility that boys and girls should share in the prevention of these

127 diseases, including through vaccination. They should convey the message that due to the

128 mode of HPV transmission, boys owe it to the girls they sexually interact with to be

129 vaccinated, particularly in areas where the rate of unvaccinated girls is high.

131 The long-awaited recommendation statement for universal HPV vaccination has been

132 received with enthusiasm by a large part of the French medical community. However, we

133 need to acknowledge the challenges ahead of us in implementing this recommendation so

134 as to overcome them. In particular, the issue of HPV vaccine shortages leading to the WHO

135 recommendation to prioritize girls versus boys, which fuelled anti-vaccination movements,

136 should not hinder progress towards achieving universal HPV vaccination in France. The

137 temporary WHO recommendation to pause vaccination programs in boys in all countries

138 could be legitimately justified by equity and solidarity considerations, but careful

139 application on a case-by-case basis according to the specific context of the countries seems

140 also warranted. As often is the case, one size does not fit all. In France, strictly following

141 these recommendations risks conveying false messages that HPV vaccine is not beneficial

142 for boys and by extension for girls, further impacting their low vaccination uptake.

143 International stakeholders should constructively engage in dialogue with vaccine

144 manufacturers in order to address and minimise the impact of this HPV vaccine supply

145 shortage on both girl and boy vaccination. In the future, a possible solution to both global 
146 shortages and perhaps low coverage would be to reduce the number of doses required. The

147 results of studies looking at the effectiveness of single-dose schemes are eagerly awaited. If

148 efficacious, the single-dose vaccination might represent a more affordable and sustainable

149 strategy for better and equitable coverage to prevent diseases in both women and men in

150 all settings.

\section{REFERENCES}

152

153 1. WHO | World Health Organization [Internet]. [cited 2019 Dec 13]. Available from:

154 https://www.who.int/immunization/monitoring_surveillance/en/

155 2. European Centre for Disease Prevention and Control. Public consultation on draft

156 guidance for introduction of HPV vaccines in EU countries: focus on 9-valent HPV vaccine

157 and vaccination of boys and people living with HIV. [Internet]. 2019 [cited 2019 Dec 13].

158 Available from:

159 http://publications.europa.eu/publication/manifestation_identifier/PUB_TQ0319241ENN

$1603 . \quad$ La HAS recommande de vacciner aussi les garçons contre les papillomavirus

161 [Internet]. Haute Autorité de Santé. [cited 2019 Dec 16]. Available from: https://www.has-

162 sante.fr/jcms/p_3135747/fr/la-has-recommande-de-vacciner-aussi-les-garcons-contre-les-

163 papillomavirus

164 4. Communiqué-HPV-2019.03.21.pdf [Internet]. [cited 2019 Dec 13]. Available from:

165 https://afpa.org/content/uploads/2019/03/Communiqu\%C3\%A9-HPV-2019.03.21.pdf

166 5. Larson HJ. The biggest pandemic risk? Viral misinformation. Nature.

167 2018;562(7727):309.

168 6. Cholet CCHD. CTIAP* Centre Hospitalier de Cholet: L'OMS appelle les États à

169 suspendre la vaccination anti-HPV (GARDASIL $\AA$, GARDASIL 9®, etc.) chez les garçons

170 [Internet]. CTIAP* Centre Hospitalier de Cholet. 2019 [cited 2019 Dec 13]. Available from:

171 http://ctiapchcholet.blogspot.com/2019/12/loms-appelle-les-etats-suspendre-la.html

172 7. WHO | Weekly Epidemiological Record, 22 November 2019, vol. 94, 47 (pp. 541 -

173 560) [Internet]. WHO. [cited 2020 Feb 19]. Available from:

174 https://clicktime.symantec.com/3XmFNw9o67en2LX1Fpyzi4M6H2?u=http\%3A\%2F\%2Fw

175 ww.who.int\%2Fwer\%2F2019\%2Fwer9447\%2Fen\%2F

176 8. Wellcome Global Monitor 2018 | Wellcome [Internet]. [cited 2019 Aug 14]. Available

177 from: https://wellcome.ac.uk/reports/wellcome-global-monitor/2018 
178 9. Ten threats to global health in 2019 [Internet]. [cited 2019 Dec 13]. Available from:

179 https://www.who.int/emergencies/ten-threats-to-global-health-in-2019

180 10. Cohen R, Martinot A, Gaudelus J, Subtil D, Stahl J-P, Pujol P, et al. Infant mandatory 181 vaccinations: Confirmation of a positive impact. Med Mal Infect. 2020 Feb;50(1):74-7.

182 11. Walling EB, Benzoni N, Dornfeld J, Bhandari R, Sisk BA, Garbutt J, et al. Interventions 183 to Improve HPV Vaccine Uptake: A Systematic Review. Pediatrics. 2016;138(1).

184 12. Nau J-Y. [Hepatitis B: a controversy for the French]. Rev Med Suisse. 2008 Feb 185 13;4(144):440.

186

187 Author's contributions

188 FD and OL have participated in the redaction of the manuscript and the revision process. FV 189 and RC have participated in the revision process. All authors have approved the final 190 manuscript.

\section{Acknowledgment}

192 A sincere thank you to Pr Philippe Mayaud for his diligent editing and reviewing of this

193 manuscript for English language.

195 Funding

196 The authors received no specific funding for this work.

\section{Conflict of interest}

198 FD declares that MSD has covered registration fees, transport and accommodation costs for

199 attendance to a conference and a research grant (Merck Investigator Studies Program HPV

200 Grant 2018). FV and RC have participated to scientific board for GSK and MSD and were 
201 investigators for GSK and MSD studies. OL served as principal investigator for vaccine

202 clinical trials (MSD, GSK bio, Sanofi Pasteur, Janssen, Pfizer) and participated to advisory

203 boards (Sanofi Pasteur, MSD, GSK bio, Janssen, Pfizer). 